\title{
Subjective Experiences of the Benefits and Key Elements of a Cognitive Behavioral Intervention Focused on Community Work Outcomes in Persons With Mental IIIness
}

Kukla, Marina PhD; Strasburger, Amy M. MA; Salyers, Michelle P. PhD; Rattray, Nicholas A. PhD; Lysaker, Paul H. PhD

\begin{abstract}
New research suggests that group-based cognitive behavioral therapy (CBT) may help improve employment outcomes in persons with mental illness, yet the effects and potential key elements facilitating change in such interventions are unclear. Utilizing a mixed methods approach, this study examined the perspectives of persons with mental illness after participating in a pilot study of the "CBT for Work Success" intervention. Findings demonstrate that participants valued the intervention and perceived that it assisted them in achieving work goals. Therapeutic effects included improved self-efficacy, work motivation, enhanced sense of self as workers, and increased beliefs that work success is attainable. CBTw elements perceived to be important in facilitating work goals included cognitive restructuring, behavioral coping strategies, problem solving work barriers, meaningful reflection on oneself as a worker, and important factors associated with the group process. The authors discuss the implications of these findings and future research directions.
\end{abstract}

Keywords: Employment, work, cognitive-behavioral, therapy, mental illness

This is the author's manuscript of the article published in final edited form as:

Kukla, M., Strasburger, A. M., Salyers, M. P., Rattray, N. A., \& Lysaker, P. H. (2017). Subjective Experiences of the Benefits and Key Elements of a Cognitive Behavioral Intervention Focused on Community Work Outcomes in Persons With Mental Illness. The Journal of nervous and mental disease, 205(1), 66-73.

https://doi.org/10.1097/NMD.0000000000000601 
Introduction

Vocational dysfunction is a substantial problem in persons with mental illness, with unemployment rates of up to $80 \%$ (cite SAMHSA 2012), leading to negative, quality of life, clinical, and psychosocial outcomes (Kukla et al., 2012; Luciano et al., 2014). In addition, poor employment outcomes result in serious financial issues, including low income (Zivin et al., 2011) and difficulties meeting basic life needs, such as food and shelter (Elbogen et al., 2012). Supported employment (SE), an evidenced-based model of individualized employment services, assists many persons with mental illness attain competitive work and avoid these negative consequences; yet, one-third or more are "non-responders" to SE (Marshall et al., 2014). These non-responders continue to struggle with unemployment; others who obtain jobs with the assistance of SE may have patterns of inconsistent vocational functioning marked by short job tenure and multiple job starts and losses over time (e.g., Bond \& Kukla, 2011; Cook et al., 2016). In response, there has been a call for interventions to augment SE and enhance employment outcomes (e.g., Drake \& Bond, 2011).

One promising approach, cognitive behavior therapy (CBT), has most often been used to ameliorate symptoms across a range of mental health disorders; however, findings regarding the impact of CBT on functioning have been mixed and effect sizes are small (Hofmann et al., 2012). One potential explanation for the dearth of positive findings in this area is that the majority of CBT interventions do not focus on functioning as a primary target of treatment. For instance, while these interventions aim to restructure thoughts about mental health symptoms and increase coping surrounding such symptoms, they do not directly address domains of instrumental role functioning and hence have less beneficial impact in these areas. In response, 
CBT interventions have begun to arise that emphasize correcting unhelpful cognitions and tailor behavioral strategies directly pertinent to deficits in functioning. For example, interventions for persons with severe mental illness combining CBT with social skills training that include content adapted for interpersonal settings have demonstrated positive benefits over time with regard to independent living skills and social skills acquisition (Granholm et al., 2013).

Evidence suggests that applying cognitive behavioral techniques to the domain of employment may be fruitful. For instance, a cognitive intervention focused on protected noncompetitive work experiences have found positive effects on work performance and job tenure in persons with schizophrenia (Lysaker et al., 2009). In addition, extant research has demonstrated that dysfunctional beliefs about one's ability to excel vocationally seriously damage work outcomes (Gallo, 1994). Specifically, people with severe mental illness endorse the belief of low likelihood of success at work, even with assistance (e.g., Roe, 2001). In addition, low self-esteem among persons with mental illness in a work program is associated with poor work outcomes (Kukla et al., 2014). Relatedly, in this population, unemployment is linked with poor self-esteem (Corbière et al., 2009), more defeatist beliefs (Campellone et al., 2016), and reduced self-efficacy (Waghorn et al., 2005) regardless of actual capabilities (Siu et al., 2010). Furthermore, recent studies examining both patient and provider perspectives have identified low work-related confidence and low motivation as major barriers to successful work outcomes among persons with mental illness receiving SE services (Corbière et al., 2011; Kukla, et al., 2015a; Kukla et al., 2016). In addition, the ways in which persons with mental health disorders think about themselves and work has been qualitatively linked with community work 
success (Kukla et al., 2015b; Williams et al., 2016). Lastly, across qualitative studies examining employed persons with mental illness, job tenure has been associated with one's perception of competence and efficacy related to the job (Williams et al., 2016). In this regard, work may present a threat to the self, resulting in lowered belief in one's ability to perform job tasks and difficulty maintaining a job; thus, it has been recognized that in such common situations, interventions are needed to target these person-level barriers and prevent job loss (Siu et al., 2010).

In response to this unmet need, a new CBT intervention targeting competitive work outcomes was developed. Designed to augment evidence based supported employment services, the Cognitive Behavioral Therapy for Work Success program (CBTw) was devised to target an array of issues related to achievement in competitive work, intervene with problematic thoughts and feelings about work, and increase adaptive coping behaviors that can be directly utilized during the job search and/or job maintenance phases. Preliminary evidence demonstrates that CBTw intervention is associated with significantly improved rates of job acquisition in the community among persons with mental illness (Kukla et al., 2016). However, despite these promising findings, the processes through which improvement occurs in CBT interventions geared toward community role functioning is largely unknown. While there is emerging evidence that beneficial changes to dysfunctional thinking are primary elements associated with change in CBT interventions geared toward the treatment of depression (Cristea et al., 2015), the link between elements of CBT and improvements in functioning is unclear. Even less is understood regarding how persons with mental illness may perceive the intervention and experience its effects. A more complete understanding of CBTw components 
and its therapeutic effects most essential to work functioning is crucial to further optimizing and increasing the potency of the intervention; this information will also generate hypotheses regarding key mediating variables to be tested in future larger scale studies of CBTw. Finally, the data gleaned from this study will enhance the implementation of CBTw into real world rehabilitation settings.

To address this gap, this study used a mixed methods approach to examine and describe how participants experienced the CBTw intervention, therapeutic effects, and elements of CBTw that were perceived as helpful in assisting participants to achieve their work goals in the community.

\section{Methods}

\section{Overall Design}

This mixed methods study is a secondary analysis of the perspectives of persons with mental illness who participated in a CBT intervention geared toward improving competitive employment outcomes in the community, termed the CBT for Work Success Program (Kukla, Strasburger, \& Lysaker, 2016). At the conclusion of the CBTw intervention, participants first rated their satisfaction with components of the intervention and secondly shared perceptions regarding the utility of the CBTw, and identified effects and elements of CBTw that impacted them as they worked toward their employment goals. This latter qualitative approach is supported by the work of Lewin and colleagues (2009), which notes that qualitative methods can be very useful in understanding healthcare intervention components and processes associated with change, as well as participants' overall experiences with such interventions. 
CBTw is a manualized program tailored toward employed and unemployed persons with community work goals, with 12 one-hour sessions delivered in a weekly group format. Session content emphasizes cognitive techniques designed to identify and modify maladaptive thoughts related to work; behavioral techniques intended to enhance coping and adaptive problem solving in the context of difficult emotional states (e.g. anxiety) that interfere with work functioning; stress tolerance skills specifically tailored to the work setting; and the formation of an individualized work success management plan tailored to address work barriers and capitalize on work-related capabilities and strengths. The CBTw intervention includes the following modules: Work goals and values related to work; CBT model and work; Thinking about work; Using the $4 \mathrm{~A}^{\prime}$ s to enhance health thinking; Barriers to work; Coping with stress and anxiety; Coping with anger and difficult emotions; Communication at work; Dealing effectively with people at work; Accepting and learning from feedback; Managing work success; Personal work success plan.

$\underline{\text { Sample }}$

Participants included 24 veterans who were receiving supported employment services at an urban Midwestern VA medical center. Inclusion criteria were a diagnosis of any mental disorder as confirmed through medical record review and an active goal of working in the community; participants could be currently working or unemployed and searching for work. Exclusion criteria were a major cognitive deficit or severe medical condition that would prevent participation in the intervention and/or competitive community work. Nineteen participants completed follow up assessments; their data is reported here. Those who did not complete follow-up assessments did not differ from participants who completed assessments with regard 
to demographics, background characteristics, or employment outcomes at the end of the study, p>.05.

\section{Procedure}

Participants were recruited through the SE program at the VA Medical Center in three waves in December 2014, April 2015, and August 2015 respectively. SE program staff approached eligible participants, providing them with written information about the study. Interested veterans were then contacted by the study team and provided with additional information about the study. Participants who verbally agreed were scheduled for a baseline interview and then provided written informed consent. All procedures were approved by the [UNIVERSITY] and [VAMC] internal review boards. Participants were paid $\$ 30$ for participation in post-intervention assessments and exit interviews. Assessments and interviews were conducted by research staff who were not involved in facilitation of the CBTw intervention.

Semi-structured exit interviews were conducted using the Narrative Evaluation of Intervention Interview (NEII) that was designed for use in persons with mental illness (HassonOhayon et al., 2006) with good inter-rater reliability (Roe et al., 2009). The NEIl contains 16 semi-structured questions that elicit vast information regarding participant experience and outcomes of an intervention. The NEIl identifies themes related to the extent to which participants found the CBTw helpful, specific domains of improvement, intervention processes and elements associated with change, and new skills and knowledge acquired that participants had not learned in past interventions (Roe et al., 2009).

Satisfaction with the CBTw program was assessed by (1) examining qualitative data from the NEIl as described above; (2) asking additional open-ended questions about the specific 
aspects of the CBT program (i.e., particular modules) that veterans found most helpful and unhelpful related to day-to-day work functioning, specific on the job successes, and overall vocational goals; (3) measuring overall veteran satisfaction with the $\mathrm{CBT}$ program using the Satisfaction with Services Scale (SWS), an 11-item questionnaire that was derived from the Client Satisfaction Questionnaire (Larsen et al., 1979). The SWS is scored on a 1 to 3 Likert scale ranging from "not at all" to "very" (e.g., "How satisfied are you with the amount and support and help you got from the staff?") with higher scores indicating a greater degree of satisfaction with the intervention. The SWS has been used in prior large studies of psychiatric rehabilitation (Salyers et al., 2009) and has been shown to have good internal consistency and criterion related validity (Attkisson \& Zwick, 1982).

\section{Analyses}

Quantitative analyses were conducted using SPSS 22. Descriptive statistics characterized satisfaction with the CBTw program. Qualitative analyses were conducted using an inductive, interpretative, consensus-based approach (Crabtree \& Miller, 1999; Miles \& Huberman, 1994). Using an inductive approach, two coders (first and third author) identified emergent themes regarding 1) key CBTw elements and processes associated with work achievement and 2) therapeutic effects of the intervention. Coders then met and discussed emerging themes in the data and resolved discrepancies. During the ongoing coding process, the coders wrote memos, resulting in continued revision of codes and a final a set of focused codes. Focused coding was then used to code the remainder of the responses. Dominant themes based on salience and frequency were identified (Saldaña, 2015). Data saturation was reached when no new variations on themes emerged (Morse, 1995), occurring after 16 transcripts. 


\section{Results}

Sample Descriptives. The sample of 19 participants who completed follow up interviews included 18 males (94.7\%); there were 10 African American participants (52.6\%) and 9 white participants (47.4\%). Eleven participants had a primary diagnosis of schizophrenia spectrum disorders (57.9\%); others included mood disorders (6, 31.6\%), anxiety disorders (1, 5.3\%), and personality disorder (1, 5.3\%). Three participants (15.8\%) had current substance abuse. The mean age of the sample was 57.0 years $(S D=6.2)$.

Satisfaction with CBTw. As displayed in Table 1, participants were very satisfied with the CBTw program overall. They were particularly satisfied with the knowledge and information provided during the intervention, the support and knowledge of intervention facilitators, the ease of contacting facilitators, and warmth and caring displayed by facilitators. Additionally, participants also reported satisfaction with the role of CBTw program in assisting them to strive toward their work goals.

Key CBTw Elements and Therapeutic Effects. As shown in Table 2, participants perceived that CBTw helped them achieve community work goals through four domains: 1) Factors related to the group process-universality of work difficulties manifested through normalization of the experience of vocational dysfunction in the face of mental illness, reductions in self stigma, and learning by observing other group members succeed at work; 2) Improvements in motivation to work and to meaningfully engage in the job search process; 3 ) Improvements in work-related self-efficacy; 4) Enhancements to one's sense of self as a worker, including greater insight regarding past maladaptive work patterns. 
Factors related to the group process: "I'm not alone": Nearly 95\% of participants ( $N=18$ ) commented on the important role of the group process, particularly with regard to normalization and gaining a sense that others have a range of similar work experiences. In addition, observing others succeed at work was particularly beneficial. These processes reduced self-stigma, increased hope, and reinforced the use of particular CBTw strategies, as group members engaged in their own journey toward attaining their work goals in the community. In addition, participants felt empowered by the success of others and were able to use these examples to modify their own thinking and increase their beliefs in their ability to succeed at work. For instance, one participant noted:

"I see others getting a job and I think I can do that too...the group allowed us to hear other people's opinions and where they're at and how they've made progress with work and you can compare it to your own and give you something to strive for, ways to better yourself."

Another unemployed participant commented on the support offered by others participants who were looking for work in the face of their mental illnesses and associated challenges. These relational experiences benefitted his perception of himself and his situation as he strives toward work, including a reduction in self-stigma surrounding work and mental illness. He stated:

"The (CBTw) program reminded me that I'm not the only one out here struggling as far as trying to find that place where I fit in in the job market despite our mental conditions...that's basically what we were all doing...I'm not the only person on the face of the earth with schizophrenia....watching other people go to work lets me gather 
another little glimmer of hope... and to be able to get that iota of motivation that I might need to go out there and at least apply for a job... There's a strong possibility a person might get a job even with schizophrenia...the first time you worked it might not have worked out or you couldn't get a job, but that doesn't mean that today is not a different day and something else good might happen...just because you might've had some bad experiences at work doesn't mean that every experience is going be a bad experience."

Another participant commented on the way in which interactions with other participants and the cognitive techniques taught aided in altering core beliefs about himself to better comport with work success; he noted:

"I was sitting there seeing those other guys who had problems keeping jobs...everybody had a common denominator, the same purpose of being there... their feedback on my situation and everything where the system lacks, why people think they can't work and they can't contribute something...then the [group facilitators'] feedback that we got on how to overcome that and change our thinking to be more helpful about work really helped me...the program has me back thinking that I can possibly contribute something to society."

Increased motivation to achieve work goals: Approximately $90 \%$ of participants $(\mathrm{N}=17)$ perceived that the CBTw intervention increased their motivation to strive toward their work goals, engage in the job search process, and/or succeed at work. For instance, an unemployed participant stated: 
"It's [CBTw intervention) given me the strength and motivation to just try again because I've been stuck in that mode of being hopeless and intimidated...it made me feel better about myself as far as job situations...made me feel like it isn't too late...to find a job...now I can just attack it [job search] and put myself out there again." Another participant engaged in finding a job described the widespread impact of the CBT program on sustaining motivation, influencing a new understanding of himself in light of past struggles finding a job, mental illness, and the pitfalls of unhealthy thinking; he stated: "Since I've been actively looking before the program, it [the CBTw program] just keeps me going. I'm just continuing to search...I was in the process [of looking for a job], and I actually did have an offer that didn't work out. My first thought was okay, this is another support group, meaning that I'Il probably be the same person when I leave, and I could say a bit of me changed... it did benefit me in some ways, and it gave me a different perspective on my job search, and it addressed things that I never gave any thought...It actually made me realize that too bad that I didn't know about this [CBTw] program years ago when my emotions and my psychological well-being got worse...they [group facilitators] were telling us ways to channel our negative thinking and have healthier thoughts. Because I had so many unhealthy thoughts... it [CBTw program] included some of my job struggles as far as looking and interviewing at some of the jobs and it [CBTw program] also addressed emotional and psychological problems that I endured because of my struggles with the job search and how it affected me to the point that...things just weren't working out. I just appeared to be unreliable. That's how bad the situation affected me to where I didn't look for work for a long time. This [CBTw 
program] just gave me more of an insight and now I think I can be successful and keep it going."

Improvements in work-related self-efficacy: Nearly three-quarters of participants ( $\mathrm{N}=14$;

73.7\%) improved their belief in their ability to succeed at work and achieve employment goals and often attributed these improvements to CBTw elements. For instance, one participant described the process of learning how to examine and restructure negative thoughts and apply these strategies in his life:

"I was sitting there seeing those other guys that had problems and the feedback that we got on like how to overcome and improve healthy thinking. It's a whole change of thinking because when you're in process and you think 'oh I can't do this, I can't do that' then you start 'can't-ing' everything. But, then it makes you aware that I am able to do something. I can work. My disability is my ability."

Others emphasized the ways in which they were able to modify and change their thinking regarding specific work barriers; ultimately this resulted in increased hope and sustained effort toward searching for new employment opportunities.. For example, one participant remarked on the influence of the CBTw program regarding his own capabilities:

"It gave me a good outlook on life, a positive outlook, helped me to when you feel like you can't do it, you can do it but you got to use different techniques to do it. You just can't say 'I can't do it, my legs hurt.' You got to figure out some kind of way you can work with that leg - And still work if you have to work." Another participant noted: 
“But now since I went through this [CBTw] program...I've got a lot more self-confidence. My self-esteem is up, and I really want to get a good job, not just to make money, but to know that I can do it on my own."

Further, an unemployed participant discussed the acquisition and use of behavioral strategies to address emotional states that interfere with work success, as well as cognitive restructuring to improve self-esteem and efficacy. He stated:

“I knew how to look for a job because I've done it before. I've worked all of my life, even when I was in prison, but I didn't know how to build my self-esteem up, believing I could do it, and get rid of that anxiety...to actually go get a job, and they [CBTw facilitators] taught me all of that to be able to do that...this [CBTw program] showed you ways to deal with your anxieties and all that and any other emotions that you were going through, like doing relaxation stuff. Not just emotions, but changing your thought processes for the better...like always being down on yourself and showed you to think more positive about yourself. I liked that."

Collectively, participants viewed the CBTw intervention as enabling them to identify and modify self-defeating thoughts and more fully recognize and act upon their own work capabilities.

Enhancements to sense of self as a worker: Almost three quarters of participants $(\mathrm{N}=14$;

73.7\%) reported that the CBTw intervention enhanced participants' sense of self as productive workers; this outcome occurred through a better understanding of maladaptive behavioral patterns associated with past vocational dysfunction, as well as improved clarity regarding where one fits within the world of work and as productive members of society. One participant 
discussed how the group helped him recognize past a maladaptive work pattern and devise a plan to address it in the future:

"The [CBTw] group showed how to prepare especially when you've been out of work quite awhile... what to expect and how to conduct myself to learn from past mistakes... I learned from the past and try to know what I do for the present for a better future... Quite a number of jobs I was on I had a weakness of speed at a lot of fast-paced jobs and there have been a few jobs that I was terminated from because my speed wasn't up to par... she [facilitator] would say 'how would you feel if the boss tells you that you need to work faster?' I told them that I would try to bear with it and do my best to work faster. There are times that I got discouraged, but I try to hang in there so as not to beat myself down and take things a step at a time and do my best."

In a related vein, another participant remarked on integrating his past work experiences with new insights about himself, stating:

"I was honest in [CBTw] group [about] what I felt about my past experiences. Because I walked off a job...then ended up in prison...they [my past job supervisors] wanted me to do something that I didn't want to do because I was in charge of receiving. They wanted me to be in charge of inventory control, and I didn't want that. I got angry, and I thought they [work supervisors] were being disrespectful to me, and I admitted all that in [CBTw] class. It was good to be able to take a look at yourself and how you messed your own self up. I used to blame the manager at that job, but now I blame nobody but myself, and I learned that through the (CBTw) group...I won't make that mistake again." 
A third participant illustrated how participation in the CBTw program offered an avenue of new understanding about himself, his tendencies of maladaptive thought, and a vision for a future in work that is consistent with his goal of being happy. Specifically, he remarked:

"It [CBTw intervention] made me recognize a lot of things that are involved in the process of becoming employed again, which gave me a lot of insight... How to question myself, be aware of my thinking, and to make sure that I'm happy and going forward in the job position, instead of being stuck in a job that I really don't want... that's my ultimate goal...The [CBTw] group also helped me realize that I could be my own worst enemy through doubt on a job... I have a tendency to think 'am I doing this right?' I might over think things sometimes instead of just doing what I need to do... the group made me question my own inhibition, question my own self-doubt when I'm doubting. If I'm doing the job and I'm doing it correctly, don't let my conscience ride me...I have a tendency to do that until I feel secure in the job. Now, if I'm doing the job correctly, I feel secure anyway."

By recognizing and reframing past difficulties in employment, participants were able to see themselves as successful and promising workers and to act accordingly with confidence in their own work behaviors.

\section{Discussion}

The CBTw program was developed in response to the need for interventions to augment existing vocational services and improve employment functioning in persons with mental illness who are at risk for deleterious work outcomes. Evidence from the CBTw pilot study suggests that the intervention may improve competitive work outcomes this population (Kukla et al., 
2016). Using the rich perspectives of participants, the current study takes the next step in understanding how persons with mental illness perceived the CBTw intervention and in what ways it may have influenced key outcomes. Most participants were very satisfied with the CBTw intervention and with program components, particularly the advice and knowledge acquired, support and help with work goals, and perceived competence of group facilitators. Qualitative findings expand on these quantitative results and offer hypotheses about perceived effects of CBTw and important intervention processes and elements facilitating work goals. In general, most participants believed that CBTw helped them improve and make strides toward their work goals. In addition, participants reported improvements in self-efficacy regarding the ability to work and be productive, enhanced insight and understanding of themselves in the role of worker, increased motivation to participate in the workforce, more positive beliefs surrounding the notion that vocational success is attainable, and a sense of connection with others and normalization of complex employment challenges.

Participants described using several elements of CBTw to achieve these desired effects that are central components of most CBT approaches. For instance, the identification and modification of unhealthy thinking about work, was mentioned by three quarters of participants. In this context, participants described a stronger belief in their work-related capabilities and likelihood of success on the job, a more realistic view of their vocational strengths and weaknesses, fewer defeatist beliefs surrounding employment, greater motivation, and a global endorsement of enhanced self-confidence. These findings converge with conclusions drawn in studies linking self-efficacy beliefs with improved clinical (Garratt et al., 2007) and recovery outcomes (Glasner-Edwards et al., 2007) in persons with mental illness, 
including longer job tenure (Williams et al., 2016). Using the unique perspectives of persons with mental illness, the current findings further explicate these relationships, connecting CBT with improvements in work-related efficacy, which in turn leads to work achievement.

Core behavioral techniques and coping strategies that support healthier cognitions relevant to the work setting were cited by nearly $70 \%$ of participants. For instance, several participants highlighted the process of acquiring knowledge and skills necessary to effectively engage in problem solving to address work-specific barriers; also mentioned were tools, such as relaxation techniques, to manage stress and arousal states that may manifest during the process of attaining work goals. Consistent with an established body of literature demonstrating a link between the implementation of behavioral techniques and cognitive restructuring with symptom improvement in conditions such as depression, psychosis, and substance use disorders (Bennett-Levy, 2003; Dunn et al., 2012; Jacobson et al., 1996), these current findings suggest that when tailored to functional context, cognitive and behavioral strategies may also play a chief role in work settings.

Third, participants commented on the opportunities that the CBTw intervention provided to meaningfully reflect on their work goals and their complex and individualized role as workers. CBTw incorporates narrative elements; for instance, participants were guided through exercises prompting them to write about their work story, narratives of work goals, values surrounding work and career, descriptions of ideal jobs, and their personal conceptualizations of work success. In concert with other elements of the intervention, these narrative features may have facilitated enhanced insight and understanding of cognitive and behavioral patterns influencing prior work success and those that are likely to have an impact 
on future work endeavors. This outcome is particularly important, given previous research indicating a direct association between work performance and persons with mental illness' understanding of their own thoughts and feelings, tasks that are necessary for adaptive coping and the execution of appropriate goal directed behavior at work (Lysaker et al., 2010). The current findings are also in line with emerging work demonstrating the efficacy of narrative interventions combined with cognitive therapy to treat deficits in mental illness impacting key domains of sense of self (Roe et al., 2014).

Fourth, the group setting allowed participants to connect with and observe others in their work journeys; in doing so, participants' perceived that they were not alone, their experiences with work difficulties were normalized, and self-stigma was reduced. The group process also provided the benefit of vicarious learning, as participants saw others succeed on the job and in the process of finding a job. Similarly, participants were also able to watch others effectively utilize specific behavioral and cognitive strategies toward the goal of community work. These elements common to group therapy (Yalom \& Leszcz, 2005) may have been synergistic with specific CBTw components to provide hope that achieving employment goals in spite of barriers is possible and perhaps likely, reinforce the use of the key cognitive and behavioral strategies to promote healthy thinking and adaptive coping, motivate action toward work goals, and further bolster efficacy beliefs. These findings fit with Bandura's social cognitive model outlining an interactive model of self-efficacy beliefs, outcomes expectancies, and motivation toward a task (Bandura, 1986), as well as more specific models of career success in persons with mental illness that emphasize the importance of interaction with peers have experienced work successes and model key skills and abilities necessary for effective work 
functioning (Fabian, 2000). In addition, despite heterogeneity across participants with regard to a range of background characteristics, including varying mental health disorders, these findings suggest that the goal of work was strong and unifying, allowing participants to relate to one another in meaningful ways.

The study has limitations that should be mentioned. First, this was a small pilot study conducted at one site in a Midwest city with primarily male veterans. While the sample was heterogeneous in other regards, it is unclear the extent to which these findings generalize to other groups. Second, while this study provides preliminary evidence and generates hypotheses regarding the active ingredients and potential effects of cognitive behavioral therapy interventions tailored for employment, further quantitative data is needed to support and elucidate the possible mediational model linking CBTw elements, mechanisms of action, and work outcomes. Third, other potentially noteworthy variables, such as therapeutic alliance, were not measured in this study. Because other research suggests that these effects may be important to work (Kukla \& Bond, 2009) and recovery outcomes in this population (Granholm et al., 2006), future studies of cognitive behavior therapy should examine these important general factors and their role in facilitating work outcomes. Fourth, five veterans were lost to follow-up; it is possible that these veterans had negative experiences with the intervention or perceived the impact of the intervention in a different manner. The findings that most participants who completed follow-up assessments were very satisfied with the intervention sheds some light on this limitation and could possibly indicate a biased sample or a facilitator effect. In addition, it should be noted that there was a ceiling effect regarding satisfaction scores; this may have impacted the range of responses. 


\section{Conclusions}

This mixed methods study provides important insights regarding an interrelated set of perceived elements and therapeutic effects associated with change in a cognitive behavioral intervention tailored to augment supported employment services and enhance competitive employment in persons with mental illness. Because of their feasibility and effectiveness, group-based cognitive behavioral treatments are becoming increasingly popular to treat a range of mental health disorders. Our findings add to this literature and demonstrate that a diverse group of persons with mental illness had a positive experience with the intervention and perceived that it assisted them in achieving their work goals. These findings have implications for rehabilitation and clinical professionals as they seek to bolster work success in this group. Even in the absence of the full program, core cognitive and behavioral techniques may be helpful to assist these persons to reach employment goals. Secondly, results indicate that there is benefit in providing an opportunity to reflect upon their own psychological processes and prior experiences related to work in order to address personal barriers that may interfere with vocational success. Lastly, these findings suggest that the group process played a notable role in helping participants move toward their work goals. Future research should build on these findings and further explore the benefits of the intervention, systematically explore its chief mechanisms of action, and identify optimal ways to effectively implement it into routine practice. 


\section{References}

Attkisson, C. C., \& Zwick, R. (1982). The client satisfaction questionnaire. Psychometric properties and correlations with service utilization and psychotherapy outcome. Eval Program Plann, 5(3), 233-237.

Bandura, A. (1986). Social foundations of thought and action: A social cognitive theory: Prentice-Hall, Inc.

Bennett-Levy, J. (2003). Mechanisms of change in cognitive therapy: The case of automatic thought records and behavioural experiments. Behavioural and Cognitive Psychotherapy, 31(03), 261-277.

Bond, G. R., \& Kukla, M. (2011). Is job tenure brief in individual placement and support (IPS) employment programs? Psychiatric Services, 62(8), 950-953.

Campellone, T. R., Sanchez, A. H., \& Kring, A. M. (2016). Defeatist Performance Beliefs, Negative Symptoms, and Functional Outcome in Schizophrenia: A Meta-analytic Review. Schizophrenia Bulletin, sbw026.

Cook, J. A., Burke-Miller, J. K., \& Roessel, E. (2016). Long-Term Effects of Evidence-Based Supported Employment on Earnings and on SSI and SSDI Participation Among Individuals With Psychiatric Disabilities. American Journal of Psychiatry.

Corbière, M., Lanctôt, N., Sanquirgo, N., \& Lecomte, T. (2009). Evaluation of self-esteem as a worker for people with severe mental disorders. Journal of Vocational Rehabilitation, 30(2), 87-98.

Corbière, M., Zaniboni, S., Lecomte, T., Bond, G., Gilles, P.-Y., Lesage, A., \& Goldner, E. (2011). Job acquisition for people with severe mental illness enrolled in supported employment programs: A theoretically grounded empirical study. Journal of Occupational Rehabilitation, 21(3), 342-354.

Crabtree, B. F., \& Miller, W. L. (1999). Doing qualitative research (2nd ed. Vol. 3). Thousand Oaks, CA: Sage.

Cristea, I. A., Huibers, M. J., David, D., Hollon, S. D., Andersson, G., \& Cuijpers, P. (2015). The effects of cognitive behavior therapy for adult depression on dysfunctional thinking: $A$ meta-analysis. Clinical psychology review, 42, 62-71.

Drake, R. E., \& Bond, G. R. (2011). IPS supported employment: A 20-year update. American Journal of Psychiatric Rehabilitation, 14, 155-164.

Dunn, G., Fowler, D., Rollinson, R., Freeman, D., Kuipers, E., Smith, B., . . Garety, P. (2012). Effective elements of cognitive behaviour therapy for psychosis: results of a novel type of subgroup analysis based on principal stratification. Psychological medicine, 42(05), 1057-1068.

Elbogen, E. B., Johnson, S. C., Wagner, H. R., Newton, V. M., \& Beckham, J. C. (2012). Financial well-being and postdeployment adjustment among Iraq and Afghanistan war veterans. Military medicine, 177(6), 669-675.

Fabian, E. S. (2000). Social cognitive theory of careers and individuals with serious mental health disorders: Implications for psychiatric rehabilitation programs. Psychiatric Rehabilitation Journal, 23(3), 262-269.

Gallo, K. M. (1994). First person account: Self-stigmatization. Schizophrenia Bulletin, 20(2), 407. 
Garratt, G., Ingram, R. E., Rand, K. L., \& Sawalani, G. (2007). Cognitive processes in cognitive therapy: Evaluation of the mechanisms of change in the treatment of depression. Clinical Psychology: Science and Practice, 14(3), 224-239.

Glasner-Edwards, S., Tate, S. R., McQuaid, J. R., Cummins, K., Granholm, E., \& Brown, S. A. (2007). Mechanisms of action in integrated cognitive-behavioral treatment versus twelve-step facilitation for substance-dependent adults with comorbid major depression. J Stud Alcohol Drugs, 68(5), 663-672.

Granholm, E., Auslander, L. A., Gottlieb, J. D., McQuaid, J., \& McClure, F. S. (2006). Therapeutic Factors Contributing to Change in Cognitive-Behavioral Group Therapy for Older Persons with Schizophrenia Journal of Contemporary Psychotherapy, 36(1), 31-41.

Granholm, E., Holden, J., Link, P. C., McQuaid, J. R., \& Jeste, D. V. (2013). Randomized controlled trial of cognitive behavioral social skills training for older consumers with schizophrenia: defeatist performance attitudes and functional outcome. The American Journal of Geriatric Psychiatry, 21(3), 251-262.

Hasson-Ohayon, I., Kravetz, S., Roe, D., David, A. S., \& Weiser, M. (2006). Insight into psychosis and quality of life. Comprehensive psychiatry, 47(4), 265-269.

Hofmann, S. G., Asnaani, A., Vonk, I. J., Sawyer, A. T., \& Fang, A. (2012). The efficacy of cognitive behavioral therapy: a review of meta-analyses. Cognitive therapy and research, 36(5), 427-440.

Jacobson, N. S., Dobson, K. S., Truax, P. A., Addis, M. E., Koerner, K., Gollan, J. K., . . Prince, S. E. (1996). A component analysis of cognitive-behavioral treatment for depression. Journal of consulting and clinical psychology, 64(2), 295.

Kukla, M., Bond, G. R., \& Xie, H. (2012). A prospective investigation of work and nonvocational outcomes in adults with severe mental illness. The Journal of nervous and mental disease, 200(3), 214-222.

Kukla, M., Bonfils, K. A., \& Salyers, M. P. (2015a). Factors impacting work success in Veterans with mental health disorders: A Veteran-focused mixed methods pilot study. Journal of Vocational Rehabilitation, 43(1), 51-66.

Kukla, M., Davis, L. W., \& Lysaker, P. H. (2014). Cognitive behavioral therapy and work outcomes: correlates of treatment engagement and full and partial success in schizophrenia. Behavioural and Cognitive Psychotherapy, 42(05), 577-592.

Kukla, M., McGuire, A. B., \& Salyers, M. P. (2016). Barriers and Facilitators Related to Work Success for Veterans in Supported Employment: A Nationwide Provider Survey. Psychiatric Services, 67, 412-417. DOI:10.1176/appi.ps.201500108

Kukla, M., Rattray, N. A., \& Salyers, M. P. (2015b). A mixed methods study examining work reintegration experiences from the perspectives of Veterans with mental health disorders. Journal of Rehabilitation Research and Development, 52(4), 477-490.

Kukla, M., Strasburger, A. M., \& Lysaker, P. H. (2016). A cognitive behavioral therapy intervention targeting competitive work outcomes for persons with mental illness. Psychiatr Serv., 67, 697. DOI: 10.1176/appi.ps.670503.

Larsen, D. L., Attkisson, C. C., Hargreaves, W. A., \& Nguyen, T. D. (1979). Assessment of client/patient satisfaction: development of a general scale. Eval Program Plann, 2(3), 197-207. 
Lewin, S., Glenton, C., \& Oxman, A. D. (2009). Use of qualitative methods alongside randomised controlled trials of complex healthcare interventions: methodological study. Bmj, 339, b3496.

Luciano, A., Bond, G. R., \& Drake, R. E. (2014). Does employment alter the course and outcome of schizophrenia and other severe mental illnesses? A systematic review of longitudinal research. Schizophrenia research, 159(2), 312-321.

Lysaker, P. H., Davis, L. W., Bryson, G. J., \& Bell, M. D. (2009). Effects of cognitive behavioral therapy on work outcomes in vocational rehabilitation for participants with schizophrenia spectrum disorders. Schizophr Res, 107(2-3), 186-191.

Lysaker, P. H., Dimaggio, G., Carcione, A., Procacci, M., Buck, K. D., Davis, L. W., \& Nicolò, G. (2010). Metacognition and schizophrenia: the capacity for self-reflectivity as a predictor for prospective assessments of work performance over six months. Schizophrenia research, 122(1), 124-130.

Marshall, T., Goldberg, R. W., Braude, L., Dougherty, R. H., Daniels, A. S., Ghose, S. S., . . Delphin-Rittmon, M. E. (2014). Supported employment: Assessing the evidence. Psychiatric Services, 65(1), 16-23.

Miles, M. B., \& Huberman, A. M. (1994). Qualitative data analysis: An expanded sourcebook: Sage.

Morse, J. M. (1995). The significance of saturation. Qualitative health research, 5(2), 147-149.

Roe, D. (2001). Progressing from patienthood to personhood across the multidimensional outcomes in schizophrenia and related disorders. The Journal of nervous and mental disease, 189(10), 691-699.

Roe, D., Hasson-Ohayon, I., Salyers, M. P., \& Kravetz, S. (2009). A one year follow-up of illness management and recovery: participants' accounts of its impact and uniqueness. Psychiatr Rehabil J, 32(4), 285-291.

Roe, D., Hasson-Ohayon, I., Mashiach-Eizenberg, M., Derhy, O., Lysaker, P. H., \& Yanos, P. T. (2014). Narrative enhancement and cognitive therapy (NECT) effectiveness: A quasiexperimental study. Journal of clinical psychology, 70(4), 303-312.

Saldaña, J. (2015). The coding manual for qualitative researchers: Sage.

Salyers, M., Godfrey, J., McGuire, A., Gearhart, T., Rollins, A., \& Boyle, C. (2009). Implementing the illness management and recovery program for consumers with severe mental illness. Psychiatric Services, 60(4), 483-490.

Siu, P. S., Tsang, H. W., \& Bond, G. R. (2010). Nonvocational outcomes for clients with severe mental illness. Journal of Vocational Rehabilitation, 32(1), 15-24.

Substance Abuse and Mental Health Services Administration (2012). 2012 CMHS Uniform Reporting System Output Tables. Rockville, Md. http://www.samhsa.gov/data

Waghorn, G., Chant, D., \& King, R. (2005). Work-related self-efficacy among community residents with psychiatric disabilities. Psychiatr Rehabil J, 29(2), 105-113.

Williams, A. E., Fossey, E., Corbière, M., Paluch, T., \& Harvey, C. (2016). Work participation for people with severe mental illnesses: An integrative review of factors impacting job tenure. Australian Occupational Therapy Journal.

Yalom, I. D., \& Leszcz, M. (2005). Theory and practice of group psychotherapy: Basic books. 
Zivin, K., Bohnert, A. S., Mezuk, B., Ilgen, M. A., Welsh, D., Ratliff, S., . . Kilbourne, A. M. (2011). Employment status of patients in the VA health system: implications for mental health services. Psychiatric Services, 62(1), 35-38. 
Table 1: Satisfaction with Services Scale Descriptives, N=19

\begin{tabular}{|c|c|c|}
\hline Item $^{1}$ & Mean & SD \\
\hline 1. How helpful has the CBT group been for you? & 2.7 & 0.5 \\
\hline 2. How warm and caring are the group facilitators? & 3.0 & 0.2 \\
\hline 3. How satisfied are you with what you did during the group sessions? & 2.5 & 0.6 \\
\hline 4. How convenient were the group sessions? & 2.8 & 0.4 \\
\hline 5. How easy was it to get in contact with a group leader? & 2.8 & 0.4 \\
\hline 6. How knowledgeable are the group leaders? & 3.0 & 0 \\
\hline $\begin{array}{l}\text { 7. How helpful have the group leaders been in helping you with your } \\
\text { work goals? }\end{array}$ & 2.7 & 0.6 \\
\hline $\begin{array}{l}\text { 8. Considering your particular needs, how appropriate was the group } \\
\text { for helping you? }\end{array}$ & 2.7 & 0.6 \\
\hline $\begin{array}{l}\text { 9. How satisfied are you with the advice and information you got from } \\
\text { the group leaders? }\end{array}$ & 3.0 & 0 \\
\hline $\begin{array}{l}\text { 10. How satisfied are you with the amount of support and help you got } \\
\text { from the group leaders? }\end{array}$ & 3.0 & 0.2 \\
\hline 11. How satisfied are you with the frequency of the group sessions? & 2.5 & 0.6 \\
\hline SWS Item Mean & 2.8 & 0.2 \\
\hline
\end{tabular}

${ }^{1}$ Items scored on a 1 to 3 Likert scale ranging from "not at all" to "very" with higher scores indicating a greater degree of satisfaction with the intervention. 
Table 2: CBTw elements and effects associated with change - Qualitative themes

Theme Sample Quote

Group process and
universality of work
difficulties: "I'm not alone"

Increased motivation to achieve work goals

Improvements in workrelated self-efficacy

Enhancements to sense of self as a worker
...To be around people that are in the same position that you're in and listen to their stories and how your stories come together in places or not and how they worked through it or are still going through it. It brings a different view. You have more opinions, more choices that you can make... as far as my goals, it did help give me much more insight as far as my job search and it addressed things that I thought that I felt alone in, and I realized that hey, other people are thinking those things too. Like concerns that once I'm hired, could I be able to do the job? There are thoughts that I've had-would I be successful in keeping this job because of my work history in the past?...There were people going out and working on jobs, and I thought if they could get a job, then I'm gonna get a job."

"Some jobs have negatives to them, but the group made me more aware...I was going to give up on doing work and now it's motivated me back thinking that I can possibly contribute something - Even though I do have an illness, I can accomplish something...I did achieve something in the [CBTw] group."

"I got a lot more confidence from the group...Before the group I thought... 'they offered this job, I can't do that,' and instead of just trying the job and seeing how it goes, I quit. Now, I'm going to try the job and believe I can do it, give it a chance."

"The group has helped me to try to be more positive in my self talk and not jump to conclusions about all the bad things that might happen... Well, whatever does happen, I can find a positive side and not always jump right on the negative side like I usually do. There's a way out, and what I think affects my behavior, and that's helped me that way... I'd say that it [CBTw program] helped me think differently about not everything is gloom and doom... I can start out the day thinking positive things, and I can make more of a habit of being a positive person than a negative person because being negative hasn't worked for me. It never has, and it never will...Now I realize that there's ways that people will help you if you help yourself and at least put in the [job] application and make an effort." 